\title{
Can Research on Science Learning and Instruction Inform Standards for Science Education?:
}

\author{
Marcia C. Linn ${ }^{i}$ \\ Andy diSessa? \\ Roy D. Pea ${ }^{3}$ \\ Nancy B. Songert
}

(To appear in Journai of Science Education and Technotony, January. 1994)

*This paper summarizes discussions and debates that the authors have had over the last few years. The dialogue stems. in part. from our joint participation in the American Educational Research Assoctation Special Interest Group on Education in Science and Technology (SIG-EST) ieudership. This paper communicates the spirit of our thinking and does not necessarily retect the views of SIG-EST. or any other organization.

We gratefully acknowiedge the support of National Science Foundation Grant MDR 9253462 in work related to inis paper. We appreciate helpful comments from Eileen Lewis and the Computer as Learning Partner group.

This material is based upon research supported by the National Science Foundation under grant RED-915574t. Any opinions. findings, and conclusions or recommendations expressed in this publication are those of the authors and not necessarily reflect the views of the National Science Foundation.

1 School of Education. 4611 T.Wiman Hall, Universty of Calilornia, Berkeley. CA 94720, 510-643-6379

2 School of Education. Liniversizy of California. Berkeley, CA

3 Northwestern University. insutute ior the Luarning Scicnces. Evanston. IL

4 School of Educauton. Lniverste of Colorado. Boulder. CO 


\begin{abstract}
We contrast the current science education reform effort with the reforms of the 1960's and suggest how the current effort could be enhanced. We identify insights from recent research that we believe can inform the reform process. In particular. to reach all science students and also impart a cohesive view of science. We propose an "altemative models" view of scientific explanation and show how this view would contribute to retorms of (a) course goals. (b) social aspects of science learning, (c) instructional practices. and (d) roles for technology.
\end{abstract}

Key Words: Science. rechnology. models, standards 
A broad artay of organizations are participating in an effort to reform science education by sertirg science standards (Nationai Research Council. 1992: National Research Counci. : 993; Nationai Science Teachers Association. 1991: Rutherford \& Ahlgren. 1990). This effort has, at its core, a commitment to making science accessible to all students. not just future scientists (National Research Council. 1992; National Research Councii. 1993; Rutherford \& Ahlgren. 1990)

As participants in the leadership of the American Educational Research Association Special Interest Group on Education in Science and Technology (SIG-EST), we have reflectec on this process. In this paper we summarize some reactions to the documents that have emerged from the standard-setting process. We especially seek to identify insights irom recent research that apply to the process of setting standards. After contrasting the current standard-based retorm with the reforms of the 1960 's. We discuss (a) science course goals. (b) the social nature of science learning in general and equity in particuiar. (c) instructional practices, and (d) the role of technology.

\section{Comparing Reforms}

Althougn the current standard-setting efforts are targeted to all students and not just future scientists, the documents that are emerging from the process are reminiscent of the reforms of the 1960's and are, therefore. subject to the same limitations. The reforms of the $1960^{\circ}$ s were initiated primarily to incorporate modern scientific ideas into the curricuium and to improve the inquiry skills of future scientists (Salinger, 1991: Science Manpower Project (Frederick L. Fitzpatrick: Director), 1959: Welch. 1979). Technology as a component of science was neglected. although technological tools such as tilms were emphasized as enhancements to instruction.

To illustrate. Jerrold Zacharias. in setting the goals for the Physical Science Study Committee (PSSC), decided to devote ail of his attention to communicating modern scientific principles. For example, in a biography of Zacharias. Goldstein (1992.p. 162) reports this summary of the PSSC view: "Modern physics was concerned with fundamentals. It had to do with particles and the forces between them. and with their motions. not with pulleys and levers. Modern physics dealt with atoms and molecules. and with stars and planets: the machines and engines that were central features of the existing prysics courses were important but only as special applications of the science. On this there was the broadest agreement possible: if something had to be dropped for lack of time. it would be the applications. The fundamentals of the science must remain. 
This decision foclised the curriculum on future scientists. And as might have been expected. followin : the reforms of the 1960's the proportion of students taking advanced science remained tre same (Salinger, 1991: Welch. 1979).

Even the innovative. sreative curricula of the 1960's were unsuccessful in important ways. For exampie. students studying these materials still often concluded that objects released from a cur:ed path would continue on a curved trajectory (McCloskey. 1983). Even students compieting college courses at institutions like MIT retain intuitive ideas that differ from those of expert scientists (diSessa, in press). Given these diverse intuitions of studen:s completing physics courses. how can we make science more teachable and more :earnable?

It is widely believed that the reform efforts of the 1960's were limited in part because the natural scientists wro led the reforms paid too little attention to the feedback they received from preccilege teachers (Welch. 1979). Precoilege teachers commonly complained that the science materials developed by natural scientists were too difficult and that students could not learn from them. In contrast, the natural scientists believed that if the teachers were more effective, students would be able to learn the materials.

A major worry we have is that emerging science standards describe curriculum that individuals who are now successful research scientists would have preferred when they were precollege students. Such a curriculum may be laudable for those who wish to become scientists. Yet. for the vast majority of students who do not aspire to be scientists. there is $: \mathrm{m}$ and convincing evidence that the current curriculum is flawed, uninteresting, fleeting, and fundamentally irrelevant (e.g., (Linn. 1987).

A key question for those setting standards is how to measure these limitations. During the 60s, reforms retiected the perspective of the natural scientists. A challenge to the standard setting group is to reexamine this decision and to incorporate the contributions of precollege teachers and pedagogy experts. as well as those of natural scientists. Considerable evidence from investigations in science classrooms suggests that both the science curriculum and the role of the science teacher need reformulation (e.g., (diSessa. 1992; Linn \& Songer. 1991; Pea \& Gomez. 1993: Songer. 1993).

In addition, the emerging science standards documents do not appear to consider the current roles of teciriology seriously in either science or education. Fundamental understandings of :echnology are not represented. Technological toois that could enhance learning and understanding and which are now integral to the research in the 
scientific community (e.g... see Office of Science and Technology Policy. 1991: Office of Science and Technology Policy, 1992) are not acknowledged or recommended. Modes of learning and instruction that are plausible. possible, and have been demonstrated with technology are also negiecred.

Furthermore, the science standards documents relegate what most citizens are likely to consider important in science to "the back of the book." Applications of science as well as the nature of science are separated from "fundamental understandings" of science.

If scientific ideas. modes of thinking, and appiications to complex problems are not linked and related in the standards, how can we expect them to be linked and related in textbooks, teaching, and learning? How can citizens and students appreciate fundamental understandings without considering their applications? And. how can students understand the nature of science if the tension between fundamental research and applications of science is not continuously addressed?

We call on groups setting standards to rethink the overall organization of the standards. We believe that it is imperative that science. technology, the nature of science, and the application of science be linked. related. and simultaneously addressed in science courses. textbooks, and standards.

\section{Incorporating Recent Research}

As reform efforts turn from a focus on future scientists to a focus on all citizens, recent research on learning and instruction and recent insights about the social nature of learning are extremely relevant. We discuss (a) course goals. (b) the social nature of science learning, (c) instructional practices. and (d) the role of technology.

\section{Course Goals}

We call on those setting the standards to adopt two criteria for the goals for science courses taken by most citizens. First. the centrai target should be a scientifically cultivated sense of the everyday physical, biological. social, and political world rather than a schoolish version of professional science. Second, this means, in particular, that the curriculum should help students link scientific principles to improving their thinking about everyday phenomena and help students build a cohesive view of scientific knowledge. 
Science entails a diversity of expianations and models. Science instruction of the past has concentrated on the most general. comprehensive. and precise models. Many of these models are couched in formai. algebraic language. These models tend to te abstract compared to the familiar forms of everyay experience. Students have a nard time understanding what the models or iaws mean, and a harder time applying them to their personal scientific dilemmas. Rather than isolating and emphasizing the abstract perspective on science. we believe the curriculum should encourage students to develop a repertoire of alternative models as well as an appreciation for science as a search for progressively more powerful models.

Modern psychology, cognitive science and artificial intelligence have elaborated our understanding of the power of alternative models of complex phenomena. particularly highlighting qualitative. heuristic and approximate models. In addition. we have come to understand that students. aduits and scientists employ many of these models in their everyday understanding. So. these two trends-expanding the repertoire of legitimate and powerful models, and uncovering the richness in students' spontaneous modelsshould combine to alter the pedagogical agenda.

We expect students have many ideas to contribute. and we can be more patient about waiting for the most sophisticated, abstract. "correct," and formally articulated forms. We need to take a long-term perspective to see how, step-by-step, we can draw students' naive models out. refine and articulate them. This is a fundamental issue. since our educational system must focus on a broad range of students and not only on an elite who will learn science with virtually any curriculum. We need to be clever in designing intermediate models that are close enough to students naive models that they seem familiar. plausible and useful. yet can evolve naturally into more sophisticaied forms. Technological tools can enhance this process (e.g., (Linn. 1992; Pea. 1992). We begin with phenomenological models that may appear more descriptive than explanatory, limited in scope. or even incorrect in contrast to "deeper" forms. But this appearance may be deceptive. The first steps toward the deepest scientific understanding may be the most critical. By establishing a disposition to make sense of the science that is taught and the science that is experienced. we set students on a trajectory that will not culminate at the last formal science lesson. but rather continue as new scientific problems are identified in experience.

Alternative models for scientific events can be illustrated by considering perspectives on thermal events. Scientists use several alternative models to elucidate thermai events: 
moiecuiar kinetic theory, a model of hear rlow. and specific computations of changes in. for exampie. calories and degrees. The heat flow model. is often intuitively accessiole to students who are ryying to make sense of thermal events and readily simulated in the classroom le.g., (Lewis \& Linn, in press।..

Effective teaching would seek a progression of alternative explanatory models to guide instruction and link principles and applications. Thus. in early elementary years. students might have a model that focuses on observable events such as (a) sweaters keep you warmer than tee shirts, (b) the same burner heats a small pot of water to boiling before a larger pot of water at the same starting temperature, and (c) cutting up the hot lasagna into pieces will cool it faster. Middle school students might form descriptive principles about such phenomena as surface area and thermal equilibrium. By high school. students could be introduced to more sophisticated models including molecular kinetic theory. In addition. a major focus of the curriculum. if it were taught this way, would be on these alternative models and their relative usefulness to citizens and scientists. For exampie. models helpful for wilderness survival might be contrasted with those helpful for materials science.

In fac: abstract scientific models are often insufficient for grappling with complex problems. Scientists disagree on such topics as the risks and benefits of nuclear energy', the reason dinosaurs became extinct, and the evidence for global warming. Educared adults have difficulty explaining why Styrofoam is better than aluminum foil for keeping a drink cold for lunch, or why a rough, white surface is better than a mirror for reflecting light irom a flashlight to illuminate a room. There are teachable. powertul versions of scientific ideas that can help (a) transcend commonsense and naive models. (b) make better sense of the everyday world, and (c) provide a solid path for those students who will become professional scientists. We advocate what we call an "altemative models" approach to science instruction.

To acnieve these goals and to clarify this alternative models perspective. we examine the October 1992 NRC Sampler (National Research Council. 1992) from this standpoint.

The eiementary curriculum. The current NRC sampler starts with descriptive models of science. Students observe and describe the similarities and differences in objects that they ooserve naturally, such as leaves or trees.

The aiternative models approach starts with a similar descriptive perspective. but adds a focus on integrating descriptive explanations and warranting conclusions. Students would 
be encouraged to appiy explanations far more widely han they commoniy are in current elementary science courses and to seek systematic accounts of everyday scientific phenomena. For exampie. they might establish a series of materials based on their ability to keep a drink coid in a iunch box. They would compije information and then seek generalizations, comparing metals to paper to cioth. for exampie. A descriprive model of insulators would therefore be accorded stature in the eyes of students. In contrast, at least some perspectives on science education accord students descriptive models of science, the status of misconceptions (e.g., Linn \& Songer, 1991: Smitn. diSessa. \& Roschelle. in press)

By labeling student ideas as misconceptions we criticize students for being accurate observers (Lewis $\&$ Linn. in press). Thus, in the early grades. students often describe phenomena in ways that could contradict the descriptions offered by scientists. They might say (a) objects. when kicked. tend to go in the direction kicked. (b) objects in motion tend to come to rest. (c) sounds die out and (d) wool warms you up. The alternative models approach might elaborate students descriptive model of motion until students concluded that objects kicked with the same degree of force come to rest at different distances depending on other conditions like the surtace on which the object travels.

Extensive evidence demonstrates that young students are capable of thoughtful generalizations (Carey, 1985). Yet the standards described in the sampler seem to imply that students are limited to description that lacks functional context or explanatory intent. This is an outmoded interpretation of developmental constraints that fails to acknowledge the intellectual work of young students and is reminiscent of the nature study movement of the 1900s and the unguided discovery activities of the 1980s (Holmes. 1904: Underhill. 1941).

The middle school curriculum. The NRC sampler recommendations for middle school differ substantially from the alternative models approacn. The sampler suggests teaching 5 th through 8 th graders molecular models. mathematical formulations for mechanics, and other abstract scientific explanations. These models do not map directly onto students' observations and start many students on the path of memorizing rather than comprehending science. We recommend that these models be postponed to the 9 th through 12 th grades. and that, instead. in the 5 th through 8 th grades. students focus on models that are more principled and mechanistic than those encountered in the early elementary grades. Students would describe the heating and cooling of objects in terms 
of heat flow, they would describe electricity in terms of relative electrical power. and they would develop quaitative mociels for motion. The idea of a mechanism or an explanation would become a more expiicit iocus of the 5 th through 8 th grades and students would systematically compile evidence that warranted their observations and conjectures. Students might disentangie the effects of mass and surface area on the heating of objects. but they would still focus on heat in a macroscopic fashion rather than in a microscopic fashion.

The high school curriculum. In the 9 th through 12 th grades, students would encounter new level models that were more abstract and. in some courses. mathematically formal. They would return to the same issues and problems that they faced in the middle grades and reinterpret the information and observations that they had using these new models. The advantage of altemative models would now become very clear because students would see the progression from a descriptive to a mechanistic to an abstract explanation for the same event. Thus. they would understand a great deal about scientific investigation, and at the same time, they would have a much richer. more qualitative understanding of everyday scientific phenomena than is achieved in the typical curriculum. This approach is reflected in the work of White on electricity (White \& Frederiksen, 1990); Linn on thermal events (Linn, 1992), Minstrell in mechanics (Minstrell, 1982), Pea in optics (Pea. Supusic. \& Allen, in press), and Clement on mechanics (Clement. 1982).

Advantages of the alternative models approach. The alternative models approach makes the inquiry skills described in the sampler an integral part of science learning rather than an additional topic. In every scientific study students would be analyzing the nature of their own explanations and the evidence that they used to warrant their conclusions. In this sense. they would be active participants in making sense of scientific phenomena just like scientists. Instead of trying to make sense of phenomena that they could not observe, students would be making sense of immediately observable phenomena up until at least the 9 th grade.

The alternative models approach also has a tremendous advantage in fostering integrated understanding. By helping students contrast the various explanations that they themselves use for everyday scientific events. students are more likely to see the relevance of their own observations to science. Instead of encouraging students to distinguish their own observations from classroom science, which happens so often today, the curriculum would help students integrate these observations with scientific 
principles. Rather than isolating ideas about scientific inquiry. students wouid seek evidence to warrant their own modei and to distinguish among models.

The greatest difficulty of an alternative models approach is its demand on students. Whereas abstract models introduced eariy in the curriculum cause students a great deal of trouble, alternative explanations ior complex and ambiguous phenomena depending on the purpose of the explanation are. in fact, much more challenging. Vevertheless. in our estimation, explaining complex and ambiguous everyday problems is also much more rewarding to students. In contrast. even when students gain a glimmer of understanding of abstract scientific models, they often fail to apply this information to everyday phenomena because they cannot map the abstract information onto observed scientific phenomena (e.g., Gunstone. Gray, \& Searle. 1992). For example, using a molecular kinetic theory to explain why a metal spoon in boiling water feels hotter than a wooden spoon is far more complex than reiying on a heat-flow model. An alternative models approach to understanding motion may start with phenomenological. approximate models. and later add more abstracted models as an illumination or "reexperience" of prior models. There are times when qualitative models are more useful than abstract models. And, as a result, the qualitative models end up supporting students as they attempt to make sense of more abstract models. They help students acquire an intermediate competence between intuitive beliefs and more sophisticated. abstract models.

\section{Instructional practices}

The alternative models approach offers more support for the efforts to make sense of science familiar to precollege teachers and educated adults than do the models found in the typical science curriculum. Teachers often consuruct views of themselves as purveyors of scientific information, yer this presents an immediate difficulty because few teachers have all the information that students might want. The alternative models approach changes the focus from one of providing information to one of supporting conjectures and seeking commonalities in evidence.

Precollege teachers take the role of fostering. facilitating. and supporting students as they make sense of science. The locus of responsibility for scientific understanding remains primarily with the student. Just as we expect students to continuously refine and reformulate their scientific ideas. so can we expect teachers to continuously retine and reformulate their ideas about how to teach science. Teachers are most effective when 
they can reflect. refine. and enhance their practice rather than when they are constanty evaluated. criticized. and scrutinized.

There is widespread belief that science teaching would be more effective if the teachers knew more science. This may well be the case. However, the amount of science that teachers need to know should certainly not exceed that achieved by most scientists in our society. Those completing teacher preparation programs must be prepared to teach any science and often science and mathematics. A realistic view of what can be learned is needed.

It appears inevitable that teachers will be responsible for helping students understand material that they themselves are also in the process of understanding. Furthermore. it is likely that teachers as well as students will hold descriptive and intuitive models of the phenomena relevant to the topics that they are teaching. We need methods for science instruction that take advantage of these descriptive and intuitive ideas that both students and teacners develop over the course of their lives. These are important accomplishments that need to be refined rather than ridiculed. It is both irresponsible and unrealistic to develop science standards that are unteachable (see Smith et al., in press).

\section{Social Nature of Science Learning}

The scientific work of gathering evidence and distinguishing among models for scientific phenomena is social in nature. In the workplace, research teams grapple with making sense of scientific evidence. Large collaborations such as the Human Genome Project and the nigh energy physics groups are necessary for advance in many fields. And. scientinc disputes are a reputable investigative tool for probing and refining bodies of evidence.

To engage students in the social aspects of science, the dilemmas must be personally meaningful. The alternative models approach, with its emphasis on linking scientific ideas to everyday phenomena makes the curriculum more personally meaningful for students. Thus, the abstract models of motion taught for frictionless surfaces in many middle grade science curricula are in fact inadequate for explaining most naturallyoccurring phenomena. A more sound and solid foundation for future instruction would be one where students worked at the intersection between their observations and the development of a model of observed phenomena. Thus. students would focus on building a mode: to explain the observed phenomena. and then. on adjusting the model to the 
realities of their obsenations. Similarly the formai mathematicai modeis and abstract principles of science are clumsy when used to explain most everyday thermal events and many aspects of sound propagation and light transmission as well. Thus discussions of alternative models. explanations for naturaily-occurring everyday scientific phenomena. and alternative forms of evidence reinforces for students the exploratory nature of science and provides a greater appreciation of the broad range of scientific activity that exists in our society.

Our advocacy of an altemative models approach includes an emphasis on design-of machines. of problem solutions, of explanations, and of investigations. Design problems frequently lead to effective scientific discourse. Students elaborate and refine their scientific models in the context of familiar or easily understood goals. Here the nature of science and the role of technological advance is particularly important. Introducing the concept of design and its social components early in the curriculum illustrates important aspects of how science works. Design exemplifies the scientific investigation skills that students are likely to use in their lives and engages students in social interactions relevant to science.

In advocating emphasis on the social nature of science we advocate, as well, respect for the diversity of views and opinions held by members of the classroom community. Recent reports and studies demonstrate that women students are often shortchanged in social settings (Wellesley College Center for Research on Women. 1992). In our own science classroom studies we have seen opinions disregarded and student contributions dismissed on the basis of group membership (Agogino \& Linn. 1992 May-June: Linn $\&$ Songer, 1991\%. Since fewer women than men participate in careers in science. what seems to happen is that individuals. often unconsciously, expect less of women in scientific discussions, and are more likely to dismiss the opinions of women. The situation is further exacerbated by the social roles society has constructed for men and women. Assertive discourse strategies that are sanctioned for men may backfire when used by women.

Thus: at the same time as we advocate encouraging students to engage in the social discourse of science. we also advocate diligent attention to potential unintended consequences of such activities. Setting a goal of "science for all" creates an opportunity to ensure that all students participate as respected members of the scientific classroom community. 
Role of Technology

Information technologies san also support the alternative modeis approach to instruction. Emerging standards, however. are notoriously silent about the fact that information technologies play fundamen:al roles in scientific inquiry. Scientists use computers to illustrate models to explain ineir observations. and to display data for purposes of scientific visualization (Brodie et al., 1992: Kaufmann \& Smarr. 1993). Computer networks facilitate scientific discussion serving as "collaboratories" (Lederberg, Uncapher. \& co-chairs, 1989) to support electronic communications, access to scientific data, and remote control of supercomputers and other technological tools (Finholt \& Sproull, 1990: National Science Foundation. 1991 June; Office of Science and Technology Policy, 1991: Office of Science and Technology Policy, 1992: Wolff. 1990). We believe that such tools must be integrated into science educational practice from the earliest years.

These tools are becoming more and more available to precollege students (Friedler. Nachmias, \& Linn, 1990: Linn. Songer, Lewis. \& Stem, in press: Rubin. Bruce. Rosebery, \& DuMouchel. 1988: Thornton \& Sokoloff. 1990). For example. students can use spreadsheets to create models of scientific concepts such as speed and acceleration (Hestenes, 1992).

Indeed, great progress has been made in developing comprehensible but very general computer environments in wich students can approach science as scientists do. by developing and refining their own models (e.g.. ! diSessa. Abelson. \& Ploger. 1991)..Many simulations make possible "What if..." experiments to hypothesize and examine relationships among variables. such as predator-prey populations in ecosystems, or optical effects of different materials on light propagation (Pea. i992: Richards. Barowy, \& Levin, 1992). Programs for scientific visualizations in disciplines such as climatology, atmospheric science. and oceanography support high school students as they develop models to explain g.obal warming, weather patterns, and effects of physical geography on climate (Gordin \& Pea. in press: Pea \& Gomez, 1993).

Electronic communication is also accessible to precollege students. The National Geographic Society-KidsNet networks tens of thousands of elementary school classrooms as they investigate local and national patterns of. for example. acid rain leveis. Students are participating in collaborative explorations of scientific phenomena (Levin. Riel. Miyake. \& Cohen. 1987: Waugh \& Levin, 1989). 
These technologies can augment classroom investigation and foster an alternative models approach to instruction. Such toois support precollege teachers who seek to shift their role from provider of authoritative knowiedge to inquiry guide (Blumenield et al., 1991: Ruopp, Gal. \& Pfister. 1993). Students can use these tools to explore and compare their own scientific models.

\section{Implications}

At the onset we noted that standard-setting is challenging because, on the one hand. it seeks to change the curriculum to meet the needs of all students and, on the other hand, those setring standards seem inclined to reinvent the reform projects of the 1960's. Broadening the audience for science requires accompanying changes in the goals, social interactions, and instructional practices of science.

For example, adults often remark that they have led successful and rewarding lives without understanding a single scientific concept or principle. In efforts to provide science for all. this remark is a very telling one. Successful adults almost cerainly have implicit models of everyday scientific phenomena and surprisingly powerful mechanistic understanding of complex and ambiguous scientific problems. These adults fail to see the connections between their ideas and the abstract, mathematically formal scientific ideas that form the current science curriculum. They feel that "fundamental" scientific understandings are esoteric and not relevant to their own lives. Simply spending more time and energy or more curricular effort teaching this sort of disconnected science is unlikely to change the perception of science in the eyes of most citizens. Rather. the information relegated to the back of the textbook and the back of the standards books needs to come to the front and be linked to every topic.

We believe standards for science should stress the need for citizens to link their solid observations and good descriptive models of scientific phenomena to fundamental scientific understandings to achieve reform. We fear a further bifurcation between scientific ideas of citizens and scientists: citizens may continue to take pride in their lack of understanding of textbook science and scientists may continue to ignore the pragmatic. powerful, and useful ideas that citizens have achieved. We call for an approach to science instruction that reframes the question concerning the understanding of science and that credits citizens and students with insight and ingenuity when they make sense of everyday scientific phenomena. 
We find that textbook science grabs odd fragments of the rich fabric of science and tries to pretend they are sensible. or even necessary. We need to take Einstein more seriously when he says "Science is a refinement of everyday thinking" (Einstein. 1954). Currently. we move away too quickly from everyday thinking to abstract models.

We encourage those setting standards to encompass both the needs of research scientists and the needs of citizens. We believe it is possible, although difficult, to identify a firm foundation for both groups and to ensure that both future scientists and future citizens will receive a grounding in scientific ideas that is relevant to their everyday scientific lives. In addition, we believe that students need a model of scientific reasoning that encompasses both their own efforts at description and observation and the efforts of research scientists at the leading edge of investigation. This model will, of necessity. emphasize the social nature of scientific knowledge construction and focus on the alternative models utilized in all scientific endeavor. It will feature respect for all citizens and emphasize the dangers of dismissing the opinions of those who are members of groups that have been underrepresented in science.

This approach, we believe, reflects an understanding of the ways students make sense of science. It builds on the sense-making efforts of students starting from their first observations of the world and encourages students to reflect on their own descriptive scientific theories while at the same time integrating their own ideas with more powerful ideas presented in science classes. It emphasizes the technological advances of science and also provides opportunity to use modern technologies to make models dynamic and to test altemative models. We believe that the alternative models approach advocated here wiil greatly enhance scientific understanding and go a long ways towards encouraging all students to think scientifically. 


\section{References}

Agogino. A. M. \& Linn. .1. C. (1992 May-June). Retaining female engineering students: Will eariy design experiences help? [Viewpoint Editoriai]. In M. Wilson (Ed.) NSF Direcions 2 ? 2 ): $8-9$.

Blumenfeld, P., Soloway. E., Marx. R.. Krajcik. J., Guzdial. M., \& Palincsar. A. (1991). Motivating project-based learning: Sustaining the doing, supporting the learning. Educational Psvchologist, 26(No. 3 \& 4).

Brodie. K. W. et al. (1992). Scientific Visualization, Springer-Verlag, Berlin.

Carey, S. (1985). Concepual change in childhond, .MIT Press. Cambridge. MA.

Clement. J. (1982). Students preconceptions in introductory mechanics. American Journal of Physics, $50(1): 66-71$.

diSessa, A. (1992). Images of learning. In E. De Corte. M. C. Linn. H. Mandl, \& L. Verschaffel (Eds.), Computer-hased learning environments and problem solving, Springer-Verlag, Berlin.

diSessa. A. (in press). Towards an epistemology of physics. Cognition and Instruction.

diSessa, A., Abelson. ?, \& Ploger. ? (1991). Overview of Boxer. Journal of Mathematical Behavior.

Einstein. A. (1954). Ideas and opinions [Based on Seelig. C. (Ed.), Mein weltbild], Crown Publishers. New York.

Finholt. T. \& Sprouil. L. S. (1990). Electronic groups at work. Organizational Science, 1: $41-64$.

Friedler. Y., Nachmias. R.. \& Linn. M. C. (1990). Learning scientific reasoning skills in microcomputer-based laboratories. Journal of Research in Science Teaching, 27(2): 173-191.

Goldstein. J. S. (1992). A different sort of time: The life of Jerrold R. Zacharias. scientist, engineer. educator, MIT Press. Cambridge. MA. 
Gordin. D. \& Pea. R. D. (in press ). Prospects for scientific visuaiization as an educational technoiogy. Joumal of the Learning Sciences.

Gunstone. R. F.. Gray, C. M. R.. \& Searle. P. (1992). Some long-term effects of uninformed conceptuai change. Science Education, 76(2): 175-197.

Hestenes. D. (1992). Modeing games in the Newtonian World. Americin Journal of Physics, $60(8): 732-7+8$.

Holmes, M. J. (Ed.). (1904). The third vearbook of the National Socierv for the Scientific Study of Education: Nature-Studv (Pt. II), University of Chicago Press. Chicago, IL.

Kaufmann. W. \& Smarr. L. (1993). Supercomputing and the transformation of science, Scientific American Library, New York. NY.

Lederberg, J.. Uncapher. K. \& co-chairs (1989). Towards a national collaboratory. Report of an invitarional workshop at the Rochefeller Liniversiry, March 17-18. 1989, Vational Science Foundation Directorate for Computer and Information Science. Washington. DC.

Levin. J. A., Riel. M., Miyake. N.. \& Cohen. M. (1987). Education on the electronic frontier: Teleapprentices in globally distributed educational contexts. Contemporary Educational Psvchology, 12: 254-260.

Lewis. E. L. \& Linn. .1. C. (in press I. Heat energy and temperature concepts of adolescents, naive adults. and experts: Implications for curricular improvements. Journal of Research in Science Tenching.

Linn. M. C. (1987). Establishing a research base for science education: Challenges, trends. and recommendations. Journal of Research in Science Teaching, 24(5): 191-216.

Linn. M. C. (1992). The computer as learning partner: Can computer tools teach science? In K. Sheingold. L. G. Roberts. \& S. M. Malcolm (Eds.), This vear in school science 1991: Technoingy for teaching and learning, American Association for the Advancement of Science. Washington. DC. 
Linn. M. C. \& Songer, N. B. (1991). Cognitive and conceptual change in adolescence [Reprinted in Teaching, learning and assessment in science education, Paul Chapman Publishing]. American Journal of Education, 99(4): 379-417.

Linn. M. C., Songer, N. B.. Lewis, E. L.. \& Stern. J. (in press). Using technology to teach thermodynamics: Achieving integrated understanding. In D. L. Ferguson (Ed.), Advanced technologies in the teaching of mathematics and science, Springer-Verlag, Berlin.

McCloskey, M. (1983). Naive theories of motion. In D. Gentner \& A. L. Stevens (Eds.), Mental Models, Lawrence Erlbaum Associates. Hillsdale, NJ.

Minstrell. J. (1982). Explaining the 'at rest' condition of an object. The Physics Teacher, 20: $10-14$.

National Research Council (1992). National Science Education Standards: Oct. '92 Progress Report (A working paper of the National Committee on Science Education Standards and Assessment) [Progress Report]. Washington. DC.

National Research Council (1993). National Science Education Standards: Julv '93 Progress Report (A working paper of the National Committee on Science Education Standards and Assessment) [Progress Report]. Washington. DC.

National Science Foundation (1991 June). Linking for learning: Computer-andcommunications network support for nationwide innovation in education, National Science Foundation Directorate for Education and Human Resources. Washington. DC.

National Science Teachers Association (1991). Scope and Sequence Curriculum. Washington, DC.

Office of Science and Technology Policy (1991). Grand Challenges: High Performance Computing and Communications: The FY 1992 L. S. Research and Development Program. A Report by the Committee on Physical. Mathematical, and Engineering Sciences, Federal Coordinating Council for Science, Engineering, and Technology, Executive Office of the President. Washington. DC.

Office of Science and Technology Policy (1992). Grand Challenges: High Performance Computing and Communications: The FY 1993L. S. Research and Development 
Program. A Report by the Committee on Phvsical, Mathematical. and Engineering Sciences, Federal Coordinating Council for Science, Engineering, and

Technology, Executive Office of the President. Washington. DC.

Pea. R.. Supusic. M.. \& Allen, S. (in press). ??

Pea, R. D. (1992). Augmenting the discourse of learning with computer-based learning environments. In E. De Corte, M. C. Linn. H. Mandl, \& L. Verschaffel (Eds.), Computer-based learning environments and problem solving, Springer-Verlag. Berlin.

Pea, R. D. \& Gomez. L. (1993). Distributed multimedia learning environments: The collaborative Visualization Project. Communications of the ACM, 36(5): 60-63.

Richards. J., Barowy, W.. \& Levin, D. (1992). Computer simulations in the science classroom. Journal of Science Education and Technology.

Rubin. A., Bruce. B.. Rosebery, A.. \& DuMouchel. W. (1988). Gerting an early srar: Using interactive graphics to teach statistical concepts in high school, (Proceedings of the Statistical Education Section). American Statistical Association.

Ruopp, R. R., Gal, S., \& Pfister, M. (1993). LabNet - Toward a community of practice: The case of high school physics teachers. project science, and new technologies, Lawrence Eribaum Associates. Hillsdale. NJ.

Rutheriord, F. J. \& Ahlgren, A. (1990). Science for all Americans [Earlier version appeared as: American Association for Advancement of Science (AAAS) (1989). Science for all Americans: A Project 2061 report on literacy goals in science, mathematics, and technology. Washington DC: AAAS.], Oxford University Press. New York.

Salinger, G. L. (1991). The materials of physics instruction [Special Issue: Pre-college education]. Physics Today, 44(9): 39-45.

Science Manpower Project (Frederick L. Fitzpatrick: Director) (1959). Modern high school physics: A recommended course of study (2nd ed.), Bureau of Publications. Columbia University Teacher's College, New York, NY. 
Smith. J. P., diSessa. A. A., \& Roschelle, J. (in press ı. Misconceptions reconceived: A consuructivist analysis of knowledge in transition. Journal of the Learning Sciences.

Songer, N. B. (1993). Learning science with a child-focused resource: A case study of Kids as Global Scientists. In Proceedings of the Fifteenth Annual Meeting of the Cognitive Science Societv (pp. 935-940), Lawrence Erlbaum Associates. Hillsdale. NJ.

Thomton. R. K. \& Sokoloff, D. S. (1990). Learning motion concepts using real-time microcomputer-based laboratory tools. American Journal of Phvsics, 58: 858-867 (Appendix Bi.

Underhill. O. E. (1941). The origins and development of elementary-school science, Scott. Foresman and Company, Chicago, IL.

Waugh, M. \& Levin. J. A. (1989). TeleScience activities: Educational uses of electronic networks. J Computers in Mathematics and Science Teaching, 8: 29-33.

Welch, W. W. (1979). Twenty years of science curriculum development: A look back. In D. C. Berliner (Ed.), Review of research in education (pp. 282-308), American Educational Research Association. Washington. DC.

Wellesley College Center for Research on Women (1992). How schools shortchange girls, American Association of University Women Educationai Foundation. Washington. DC.

White, B. Y. \& Frederiksen, J. R. (1990). Causal model progressions as a foundation for intelligent learning environments. Artificial Intelligence, 24(1): 99-157.

Wolff, R. S. (1990). The Macintosh scientific computing environment. Computers in Physics (July-Aug): 348-361. 
September 2, 1993

To: Andy diSessa

Roy Pea

Nancy Songer

From: Marcia Linn

Re: JSET paper

Enclosed is a copy of the final version of the paper submitted to JSET. Please review it and let me know if there are any glaring omissions or other problems. In addition, if there are any changes that need to be made in galley proofs, please inform me of those as well, and I will make the changes when the galley proofs arrive.

The paper is slated to appear in the January 1994 issues of JSET, and congratulations to all of us for completing this task. As Andy noted in his final email, this may even make a difference which would be exciting.

I will also send a copy of the paper to the NRC standards setting groups since the paper so strongly reacts to their efforts. I mentioned it to Jim Greeno who let me know that the initial commentary that we sent had been extremely helpful to his group of the standards setting committee.

Also, please consider submitting papers to ISET's SIG:EST section for subsequent issues. Already, we have a paper from the COVIS project which is currently under review. We are expecting a paper soon from the Multimedia Kiosk group, and we look forward to papers from all of you as weil. 